\title{
Organização de Centros de Especialidades Odontológicas numa Regiáo de Saúde na Bahia
}

| ${ }^{1}$ Tatiana Praxedes Rodrigues Chequer, ${ }^{2}$ Adriano Maia dos Santos I

Resumo: Este artigo analisa a organização dos Centros de Especialidades Odontológicas (CEOs) numa região de saúde e discute o percurso de implantação dos CEOs na Bahia. Trata-se de um estudo de caso, com abordagem qualitativa, por meio de entrevistas semiestruturadas, abarcando gestores diretamente envolvidos com as políticas de saúde bucal em âmbitos estadual, regional e municipal. Além disso, a análise documental foi utilizada para complementar e estabelecer interconexão com os dados produzidos nas entrevistas. A análise de conteúdo temática orientou a interpretação dos resultados. Grande parte da população baiana permanece descoberta de serviços públicos especializados para saúde bucal, sem expectativas de implantação de novos CEOs tanto na perspectiva municipal, quanto na lógica regional. Houve dificuldade de conformar uma cooperação intermunicipal na região para açôes compartilhadas em saúde bucal, assim como a agenda do governo estadual não fomentou arranjos de CEO regionais. Dessa forma, existe uma fragmentação da assistência, sem garantias na continuidade do cuidado em saúde bucal e, por conseguinte, o arrefecimento da capacidade resolutiva dos sistemas locais de saúde.

> Palavras-chave: saúde bucal; especialidades odontológicas; planejamento regional de saúde; administração de serviços de saúde.

\author{
${ }^{1}$ Instituto Multidisciplinar, \\ Universidade Federal da Bahia. \\ Vitória da Conquista-BA, Brasil \\ (tatiprax@yahoo.com.br). \\ ORCID: 0000-0002-9603-2140 \\ 2 Observatório Baiano de Redes \\ de Atenção à Saúde. Universidade \\ Federal da Bahia. Vitória da \\ Conquista-BA, Brasil (maiaufba@ \\ ufba.br). \\ ORCID: 0000-0001-9718-1562
}

Recebido em: 12/09/2019 Aprovado em: 15/03/2020 Revisado em: 29/07/2021 


\section{Introdução}

O atendimento odontológico no Brasil ocorre preponderantemente em consultório particular, ou seja, o acesso à assistência em saúde bucal é, ainda, determinado pela capacidade de pagamento por desembolso direto e/ou seguros de saúde (PERES et al., 2012; NEUMANN, 2014; CHAVES etal., 2017). Entretanto, a qualidade da saúde bucal deve ser entendida não só como resultado do acesso aos serviços de saúde, mas também estaria ligada a fatores biológicos, psicológicos e sociais; portanto, uma má condição de saúde bucal reflete a exclusão social sofrida e retrata a deficiência na qualidade de vida de uma determinada população (NARVAI; FRAZÃO, 2008). A odontologia por si só não seria capaz de resolver os problemas de saúde bucal da população, pois seria responsável por parcela dos meios de cura e prevenção de doenças orais (PINTO, 2013).

Para melhorar a condição de saúde bucal da população, precisa haver mudança no processo de trabalho e no modelo de atenção à saúde por meio de políticas públicas abrangentes (NARVAI; FRAZÃO, 2008). Assim, o modelo hegemônico, centrado nos aspectos biológicos da doença e na figura do dentista, não tem gerado impactos positivos significativos nas condiçóes de saúde bucal dos brasileiros. Além disso, o trabalho odontológico individual, apesar de contribuir, não é fator principal para que as necessidades de saúde da população sejam atendidas (SCHERER; SCHERER, 2015).

Outrossim, foi somente após a implantação do Sistema Único de Saúde (SUS) que mudanças concretas passaram a ser viáveis em direção a uma ruptura com o modelo biomédico de produção do cuidado odontológico (SILVA et al., 2013; NARVAI; FRAZÃO, 2008). Dentre essas propostas, a Estratégia de Saúde da Família (ESF) surge como dispositivo de reorientação do modelo de atenção, na perspectiva de viabilizar a integralidade, a universalidade e equidade do acesso à saúde.

Em 2004, é lançada a Política Nacional de Saúde Bucal (PNSB) que traz as diretrizes voltadas para a reorganizaçáo do cuidado em saúde bucal em todos os níveis de atenção, tendo como eixo a produção do cuidado (BRASIL, 2004). Nesta perspectiva, a PNSB intensificou a expansão e a qualificação das Equipes de Saúde Bucal (EqSB) na Estratégia Saúde da Família (ESF), bem como a organização da atençáo odontológica especializada por meio dos Centros de Especialidades Odontológicas (CEOs) e Laboratórios Regionais de Próteses Dentárias (LRPDs). Além de ações assistenciais, a PNSB enfatizou a integralidade do cuidado nas ações em saúde bucal mediante articulação de ações de vigilância e educação em saúde. 
Não obstante, é fundamental que o sistema de saúde se organize em rede para superação da fragmentação da atenção, em busca da integração dos serviços de saúde a fim de garantir a continuidade e a integralidade do cuidado (SANTOS, 2018). No entanto, muitos obstáculos são constatados para a efetivação da implementação de redes de atenção, dentre os quais se destacam baixa cobertura da APS, acesso limitado à atenção especializada, desvalorização da APS e desarticulação entre os níveis de atenção (ARAGÃO, 2016), além de aspectos relacionados à fragilidade na governança regional (GODOI et al., 2017; SANTOS; GIOVANELLA, 2014).

Com relação às práticas de saúde bucal, as diretrizes de sua política nacional estiveram em consonância com as diretrizes da regionalização, quando recomendou que os CEOs fossem fruto de planejamento locorregional e que ofertassem para a região e os municípios procedimentos clínicos odontológicos complementares aos realizados na APS (BRASIL, 2004).

No Brasil, há um grande número de municípios de pequeno porte e com baixa arrecadação, o que dificulta que os mesmos implantem seus próprios CEOs (FIGUEIREDO et al., 2016). Portanto, é fundamental a colaboração entre os entes federativos para a organização de uma rede regionalizada, a fim de garantir ao usuário a continuidade do cuidado e maior nível de resolubilidade na atenção à saúde bucal.

No entanto, a realidade da atenção em saúde bucal no Brasil ainda é marcada por um acesso excludente, tanto na APS (CHAVES et al., 2012; SANTOS et al. 2007), como nos serviços especializados (PERES et al., 2012; MANFREDINI et al., 2012). Em muitas unidades de atenção primária, o acesso ainda é estabelecido mediante triagem (TAVARES et al., 2013; BRASIL; SANTOS, 2019) e pela ordem de chegada (SANTOS; ASSIS, 2010). Por sua vez, na atenção especializada, mesmo nos municípios que implantaram os CEOs, são observados elevados tempos médios de espera (CASOTTI et al., 2014), com desempenhos insatisfatórios (GOES et al., 2012; FREITAS et al., 2016).

Tal situação é mais grave nas localidades onde não existe oferta pública de atenção especializada, pois aqueles que podem pagar recorrem aos consultórios odontológicos privados, enquanto os demais, sem encontrarem alternativa, recorrem a procedimentos mutiladores, com o intuito de resolverem condiçóes de sofrimento (MOREIRA; NATIONS; ALVES, 2007). 
Diante do exposto, este artigo analisa a organização dos CEOs numa região de saúde e discute o percurso de implantaçáo dos CEOs no estado da Bahia.

\section{Metodologia}

Trata-se de estudo de caso (YIN, 2005), com abordagem qualitativa (DEMO, 2002). A pesquisa abrangeu interlocutores de dois municípios da região de saúde de Vitória da Conquista, Bahia, e, também, gestores da Secretaria de Estado de Saúde da Bahia (Sesab).

Foram eleitos os dois únicos municípios com CEOs da região que, por sua vez, ilustram a diversidade na organização e as barreiras de acesso às açóes odontológicas especializadas (tabela 1). Além disso, os dois municípios juntos somam mais de 50\% da população da região, constituindo, por conseguinte, um corpus (universo estudado) representativo dos fenômenos regionais, pois contêm as características essenciais do universo pretendido (MINAYO, 2014). A produção de dados transcorreu de janeiro a maio de 2019.

Os resultados emergiram das análises e cruzamentos de dados produzidos por meio de sete entrevistas semiestruturadas. Nesta perspectiva, os interlocutores corresponderam à totalidade de gestores diretamente envolvidos com as políticas de saúde bucal em âmbito estadual (três gestores), regional (um gestor) e municipal (três gestores). Além disso, a análise documental foi utilizada para complementar e estabelecer interconexão com os dados obtidos nas entrevistas.

Os dados foram analisados e interpretados por meio da técnica de Análise de Conteúdo Temática (MINAYO, 2014). A pesquisa foi aprovada pelo Comitê de Ética em Pesquisa da Universidade Federal da Bahia, com o parecer n ${ }^{\circ}$ 3.100.648, de 21 de dezembro de 2018. 
Tabela 1. Características sociodemográficas e de saúde dos municípios, da região de saúde e do estado

\begin{tabular}{|c|c|c|c|c|c|c|c|c|}
\hline $\begin{array}{c}\text { Município/ } \\
\text { Região/ } \\
\text { UF }\end{array}$ & $\begin{array}{c}\text { População de } \\
\text { Zona Rural/ } \\
\text { Zona Urbana } \\
(2010)^{1}\end{array}$ & $\begin{array}{c}\text { População } \\
\text { Estimada } \\
2018^{1}\end{array}$ & $\begin{array}{l}\text { Índice } \\
\text { de Gini } \\
(2010)^{2}\end{array}$ & $\begin{array}{c}\text { Cobertura } \\
\text { de } \mathrm{ESF}^{3}\end{array}$ & $\begin{array}{c}\text { Número } \\
\text { de } \\
\mathrm{EqSF}^{3}\end{array}$ & $\begin{array}{c}\text { Cobertura } \\
\text { de EqSB }\end{array}$ & $\begin{array}{c}\text { Número } \\
\text { de CEO/ } \\
\text { Tipo }^{4}\end{array}$ & $\begin{array}{c}\text { Número } \\
\text { de CEO } \\
\text { na } \text { RCPD }^{4}\end{array}$ \\
\hline $\begin{array}{c}\text { Cândido } \\
\text { Sales }\end{array}$ & $\begin{array}{c}8.632 / \\
19.286\end{array}$ & 25.332 & 0,50 & $100 \%$ & $\begin{array}{c}10 \\
\text { ZU:07 / } \\
\text { ZR:03 }\end{array}$ & $51,74 \%$ & $01 / \mathrm{I}$ & 0 \\
\hline $\begin{array}{l}\text { Vitória da } \\
\text { Conquista }\end{array}$ & $\begin{array}{c}32.127 / \\
\mathbf{2 7 4 . 7 3 9}\end{array}$ & 338.885 & 0,55 & $43,53 \%$ & $\begin{array}{c}46 \\
\mathrm{ZU}: 28 / \\
\mathrm{ZR}: 18\end{array}$ & $42,54 \%$ & $01 /$ III & 0 \\
\hline $\begin{array}{l}\text { Região de } \\
\text { Saúde de } \\
\text { Vitória da } \\
\text { Conquista }\end{array}$ & $\begin{array}{l}205.475 / \\
422.309\end{array}$ & 641.560 & -- & $70,62 \%$ & $\begin{array}{c}177 \\
\text { ZU:85 / } \\
\text { ZR:92 }\end{array}$ & $62,67 \%$ & 02 / I e III & 0 \\
\hline $\begin{array}{c}\text { Estado a } \\
\text { Bahia }\end{array}$ & $\begin{array}{l}3.914 .430 / \\
10.102 .476\end{array}$ & 14.812 .617 & 0,62 & $72,84 \%$ & $\begin{array}{c}-- \\
\mathrm{ZU:}{ }_{--} \\
\mathrm{ZR} \mathbf{A}_{--}\end{array}$ & $55,27 \%$ & $\begin{array}{c}79 \text { / I, II } \\
\text { e III }\end{array}$ & 33 \\
\hline
\end{tabular}

Notas: UF: Unidade da Federação/ ESF: Estratégia de Saúde da Família/ EqSB: Equipes de Saúde Bucal vinculadas às Equipes de Saúde da Família/ CEO: Centros de Especialidades Odontológicas/ RCPD: Rede de Atenção à Pessoas com Deficiência/ EqSF: Equipes de Saúde da Família/ ZU: Zona Urbana/ ZR: Zona Rural.

Fontes: ${ }^{1}$ IBGE, Censo Demográfico 2010. Disponível em: https://cidades.ibge.gov.br/ Acesso em 9 dez. 2019; ${ }^{2}$ Atlas do Desenvolvimento Humano no Brasil. Disponível em: http://atlasbrasil.org.br/2013/pt/consulta. Acesso em 09 dez. 2019;

${ }^{3}$ e-Gestor Atenção Básica. Disponível em: https://egestorab.saude.gov.br/paginas/acessoPublico/relatorios/ relHistoricoCobertura.xhtml. Acesso em 9 dez. 2019; ${ }^{4}$ Cidades que possuem Centros de Especialidades Odontológicas-CEO, Coordenação Geral de Saúde Bucal-CGSB/ Ministério da Saúde-Secretaria de Atenção à Saúde-Departamento de Atenção Básica-MS/SAS/DAB, Disponível em: https://aps.saude.gov. br/ape/brasilsorridente/mapas/CEO/BA. Acesso em 9 dez. 2019.

Fonte: elaboração própria.

\section{Resultados e Discussão}

A oferta de atenção especializada em saúde bucal no estado da Bahia, segundo gestores, foi anterior à Política Nacional de Saúde Bucal (PNSB) e, logo, aos CEOs. De tal modo, em alguns municípios, os serviços especializados odontológicos eram ofertados em pontos de atenção secundária ambulatorial, como policlínicas 
municipais, bem como havia provimento de algumas especialidades em centros de referência à saúde sob a administração estadual (CT-1). No entanto, no Brasil e, consequentemente, na Bahia, anterior à PNSB, a atenção odontológica especializada era pontual, incipiente, fragmentada e restrita a poucas especialidades da área. Além disso, não modelava qualquer integração numa perspectiva de rede de serviços ou se apoiava em bases epidemiológicas (CHAVES; ROSSI; FREIRE, 2016; CHAVES et al., 2011; BRASIL, 2004).

A partir da PNSB e aporte financeiro federal, houve, na Bahia, estímulo à ampliação da oferta de açôes especializadas em saúde bucal por meio da implantação de CEOs municipais (CT-2). A PNSB, em 2004, permitiu uma rápida capilarização de açôes odontológicas mais abrangentes pelo território nacional, as quais, tendo a implantação de CEOs como estratégia para fomentar a integralidade nas ações, promoveu diversidade do escopo e expansão da cobertura à atenção especializada (FIGUEIREDO; GOES; MARTELLI, 2016).

Em agosto de 2019, havia 1.139 serviços habilitados e distribuídos em todo Brasil (BRASIL, 2019), sendo que a Bahia contava com 79 CEOs distribuídos em 72 municípios (BRASIL, 2019). Por sua vez, na regiâo de saúde de Vitória da Conquista, apesar dos 19 municípios que a compóem, apenas dois CEOs municipais estavam implantados (BRASIL, 2019). Estes dados indicam que, apesar da expansão, grande parte da população baiana permanece descoberta de serviços públicos especializados para saúde bucal, implicando descontinuidade da atençáo e importante barreira à resolubilidade das demandas apresentadas.

De acordo com gestores estaduais, nos primeiros anos de lançamento da política, houve grande interesse dos municípios no credenciamento de CEOs. Entretanto, o entusiasmo arrefeceu-se nos anos subsequentes, inclusive com o fechamento de CEOs em alguns municípios baianos. Assim, problemas no financiamento foram apontados como razóes para retrocesso ou morosidade na implantação de açôes especializadas em saúde bucal no estado (CT-2).

O financiamento do governo federal impulsionou a implantação dos CEOs em alguns municípios. Entretanto, de forma contraditória, contribuiu para que muitos deles deixassem de ofertar açóes odontológicas especializadas por meio de modalidades distintas aos CEOs. Ademais, aqueles que optaram em não implantar CEOs municipais e decidiram por ofertar essa atenção de modo compartilhado, na 
lógica de CEOs regionais, encontraram dificuldade em efetivar uma cooperação intermunicipal. Assim, segundo gestor estadual, a oferta pública da assistência especializada em saúde bucal, na Bahia, foi reduzida ou extinta em algumas localidades, porquanto nem o CEO nem qualquer outro modelo assistencial fora implantado (CT-2).

Um gestor regional revelou que, entre 2006-2013, um terceiro município da região de saúde de Vitória da Conquista, também, dispunha de CEOs. Não obstante, por considerar insuficiente o repasse da união para o custeio mensal do serviço, o gestor municipal solicitou descredenciamento. Sendo assim, alegou-se incapacidade financeira tanto em pagar como atrair profissionais para trabalhar nas especialidades ofertadas nos CEOs (CT-2). Tal descredenciamento consta em ata da $212^{\circ}$ reunião ordinária da Comissão Intergestores Bipartite da Bahia (BAHIA, 2013). Na sequência, o Ministério da Saúde, considerando a Resolução CIB no 152/2013, descredenciou o CEO do município de Barra do Choça, por meio da Portaria 1.221, de 18 de junho de 2013 (BRASIL, 2013).

Diante dessa realidade, o gestor regional considerou que a maioria dos municípios dessa região não consegue garantir o referenciamento da população às especialidades em saúde bucal e que, mesmo assim, não constatava interesse em implantar novos CEOs (CT-3). Do mesmo modo, a dificuldade em responder às demandas de especialidades odontológicas e a continuidade do cuidado foi constatada, também, em outras localidades do país, representando um desafio comum aos gestores locais (AGUILERA et al., 2013).

Vale destacar que, para a implementação de uma política, é imprescindível considerar os recursos necessários para operacionalização da mesma. Na realidade, implantar um CEO requer um aporte financeiro em que o incentivo ministerial seria responsável por uma pequena parcela do custeio do serviço. Portanto, o subfinanciamento impóe gastos elevados aos municípios e compromete as intençôes de oferta destes serviços.

Segundo a PNSB, o financiamento dos CEOs deve ser fruto de parceria entre União, estados e municípios (BRASIL, 2004). Contudo, na Bahia, assim como a maioria dos estados do país, a coparticipação estadual não é garantida (DEITOS, 2009). Deste modo, os CEOs implantados na Bahia, segundo gestores, foram custeados apenas com recursos municipais e repasses ministeriais (CT-3). 
Sendo assim, o distanciamento entre os municípios e o estado em relação aos CEOs foi atribuído à ausência de coparticipação estadual no financiamento desses estabelecimentos. Outrossim, um dos gestores evidenciou certa dificuldade em desempenhar seu trabalho como apoiador, demonstrando uma fragmentação do sistema. Isto posto, contribuía para "um processo de municipalização com baixa capacidade de interação e solidariedade entre as partes” (CAMPOS, 2006, p.427).

Por sua vez, diante de uma grande diversidade entre os municípios do país, em termos de desenvolvimento político, econômico e social, a efetivação de uma cooperação interfederativa (entre estados e municípios e entre municípios) seria fundamental para a estruturaçáo de uma rede de atenção à saúde, com o intuito de ampliar o acesso da população a qualquer nível de atenção e da capacidade resolutiva dos sistemas locais de saúde (OPAS, 2011). Em contrapartida, o modelo de descentralização da política de saúde brasileira tem sobrecarregado os municípios e gerado conflitos entre os entes federados, a partir do momento em que a provisão das açóes e serviços de saúde do sistema é de responsabilidade municipal e a partilha tripartite do financiamento do SUS é frequentemente contestada, especialmente pelos secretários municipais de Saúde que se veem desprestigiados (AGUILERA et al., 2013).

As falas dos gestores estaduais trouxeram um panorama de reduzida oferta de atenção especializada em saúde bucal no estado e pouca expectativa da ampliação por meio da implantação de novos CEOs. Outrossim, ressaltou-se não somente um desinteresse de alguns gestores municipais em implantar esse tipo de serviço, devido à escassez de recursos para o financiamento, mas também em consequência da atual política de contingenciamento federal, que congelou os gastos para a saúde (CT-4).

Nesta perspectiva, as medidas de austeridade fiscal trazem preocupaçóes com relação à sobrevivência dos CEOs e, consequentemente, da garantia da oferta de atenção especializada em saúde bucal no país. Até porque, o governo federal é o detentor do maior orçamento; logo, é o principal agente de fomento das políticas de saúde (MENDES; MARQUES, 2014). 
Tabela 2. Categorias temáticas (CT-1 a CT-4) segundo dados empíricos de gestores/ gerentes estaduais, regional e municipais

\begin{tabular}{|c|c|}
\hline $\begin{array}{l}\text { Categorias } \\
\text { temáticas }\end{array}$ & Estratos de entrevistas com gestores \\
\hline 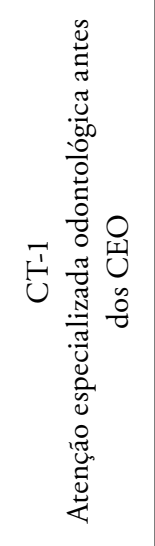 & $\begin{array}{l}\text { [...] os serviços especializados, a gente tende a pensar que só são ofertados no CEO } \\
\text { [...], mas antes de existir CEO, já existia a oferta pelo SUS de serviços especializados, } \\
\text { tanto em centros de referências, que a gente ainda tem aqui no estado [...], quanto em } \\
\text { algumas policlínicas municipais. Existem policlínicas que faziam endodontia, periodontia } \\
\text { especializada, algumas cirurgias [...] (GE1). } \\
\text { [...] a atenção especializada era bastante restrita, até um tempo atrás. [...] Vitória da Conquista, } \\
\text { Juazeiro, acho que Eunápolis, Salvador já tinham de certa forma um pouquinho estruturado; } \\
\text { não era o nome CEO, mas já tinham policlínicas que ofertavam atenção especializada, nesse } \\
\text { formato de policlínica. E recebia [recurso] por procedimento da média complexidade [...] Aí, } \\
\text { com a PNSB, a implantaçáo dos CEO e laboratórios regionais de prótese, deu um bum. Era } \\
\text { praticamente inexistente, alguns municípios é que faziam seus procedimentos, mas poucos } \\
\text { municípios. Aí, com a política, que, realmente, veio a ofertar pra o Brasil todo, de uma } \\
\text { forma institucionalizada, os procedimentos da atençáo especializada (GE2). }\end{array}$ \\
\hline 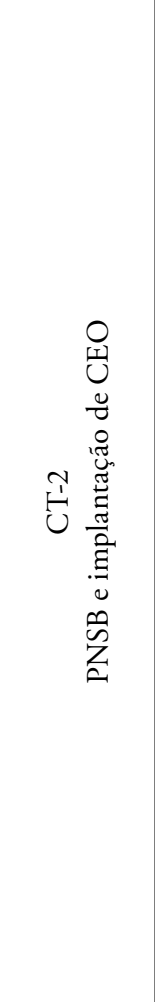 & $\begin{array}{l}\text { [...] esse CEO passando a ser custeado pelo ministério impulsionou em alguns locais, [mas] } \\
\text { em outros locais, essa oferta acabou diminuindo. Porque náo implantou o CEO e aí, os } \\
\text { municípios foram perdendo essa prática, mesmo porque, o CEO pressupóe uma lógica } \\
\text { regional, onde os municípios vizinhos podem contar com essa oferta e, aí, já que tinha o } \\
\text { CEO ali perto que ofertava, e tinha especialista e tal, pararam de ofertar no âmbito de seus } \\
\text { municípios e passaram a encaminhar pro CEO, só que encontraram uma dificuldade que } \\
\text { era justamente esse compromisso com o gestor do município que tem o CEO implantado, } \\
\text { em assumir essa demanda dos [outros] municípios (GE1). } \\
\text { [...] quando começou, realmente, a PNSB com incentivo, [...] aí, começaram alguns } \\
\text { municípios a implantar. No começo alguns municípios não tinham critério, nem aqui na } \\
\text { Bahia, nem no Brasil. Entáo, alguns municípios se interessaram e começaram a implantar } \\
\text { esse CEO. Depois teve uma diminuta reduçâo, né? Até porque, os custos do CEO, né? Tem } \\
\text { a parte do financiamento, [pois] não é um dos melhores para um serviço diante de toda } \\
\text { a complexidade da saúde bucal. Então, alguns municípios até pediram CEO, mas nunca } \\
\text { implantaram depois. Devolveram o dinheiro, outros, de fato, implantaram o serviço e } \\
\text { depois tiveram que voltar, mas alguns ainda continuam [...] (GE2). } \\
\text { [...] o [problema] que trava mais é essa questáo dos encaminhamentos à média e alta } \\
\text { complexidade. No caso do CEO, tivemos uma época que tínhamos três: Conquista, } \\
\text { Cândido Sales e Barra do Choça; depois o de Barra do Choça fechou, porque alegavam } \\
\text { que com o recurso que vinha não tinham condiçôes de pagar os profissionais, que tinham } \\
\text { dificuldade de contratar os profissionais. E ficou só Vitória da Conquista e Cândido Sales } \\
\text { que têm o CEO municipal [que] só atendem [sua própria] população. Os outros [17] } \\
\text { municípios ficam sem ter pra onde encaminhar [...] os outros municípios náo têm muito } \\
\text { interesse de implantar (GE4). }\end{array}$ \\
\hline
\end{tabular}




\begin{tabular}{|c|c|}
\hline $\begin{array}{c}\text { Categorias } \\
\text { temáticas }\end{array}$ & Estratos de entrevistas com gestores \\
\hline 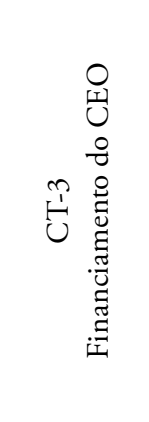 & $\begin{array}{l}\text { [...] estamos em um estado que não tem contrapartida estadual pra nenhum dispositivo de } \\
\text { saúde bucal [...]. Então, acaba que o município recebe o recurso do Ministério e tem que dar } \\
\text { todo o resto do custeio que, às vezes, não suporta manter esse serviço. [...] o município acaba } \\
\text { com quase setenta por cento do recurso de custeio de CEO, e o estado não bancava (GE1). } \\
\text { [..] fui pra um evento do Ministério da Saúde, uma primeira avaliação do Norte e Nordeste } \\
\text { dos CEO, e o coordenador apresentou os resultados; já eram sofríveis. Ele disse: "Oh, se } \\
\text { colocar esse resultado na mesa do ministro, termina o programa." Mas não se termina } \\
\text { programa desse jeito. A descontinuidade é através do quê? Tirando recurso, diminuindo } \\
\text { recurso. Ele não vai dizer: "Termina, terminou". É diminuindo recurso até dizer acabou, } \\
\text { entendeu? [...] (GE2). }\end{array}$ \\
\hline 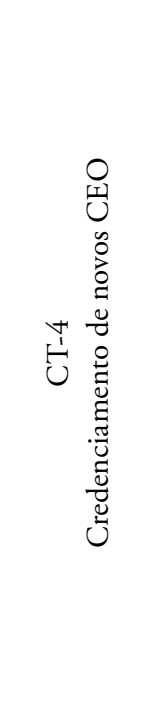 & $\begin{array}{l}\text { [...] temos, por exemplo, setenta e nove CEO, não tem dinheiro novo, e tenho uma fila } \\
\text { de espera de cinco municípios que querem CEO. O ministério não vai me dar os cinco, } \\
\text { enquanto não tirar cinco [de outro local]. [...]. Esses dias, precisou implantar dez laboratórios } \\
\text { de prótese, "me diga, quais são os dez que você quer que descredencie pra poder implantar dez } \\
\text { novos. Os piores aí do estado, me diga quais são." [...] "fiz um levantamento, aqui tem cinco } \\
\text { muito ruins". Pra gente poder dá essa fila de espera, temos quarenta e dois municípios na fila } \\
\text { de espera pra laboratório. [...] A gente só conseguiu dez. Aí, lá na negociação, tá vendo assim, } \\
\text { "cê vai querer quantos?". "Três." "Perdeu quantos?". "Sete". "Então, me dê quatro". Era assim. } \\
\text { Pernambuco! Não. Eu tenho oito, mas vou perder nove, então fica um, me dê mais um, } \\
\text { algum de Pernambuco vai pra Bahia. Desse jeito, porque não tem recurso novo [...] (GE1). } \\
\text { [...] Os gestores, todo mundo se conhece, já sabe mais a realidade. No início, houve aquele } \\
\text { bum: era CEO pra tudo quanto era lado. Implantou o CEO pelo mundo; tanto que o } \\
\text { estado da Bahia tem um bocado, mas estacionou. Agora é assim, um ou outro, entendeu? } \\
\text { E o ministério com essas políticas todas, né? Deu um freio. Primeiro se tirou um recurso } \\
\text { do Brasil Sorridente, ainda no governo de Dilma, uma das políticas públicas que perdeu o } \\
\text { recurso foi o Brasil Sorridente, né? Tão assim, quando descredenciar um, aí, vai dar aquele } \\
\text { recurso pra outro (GE2). }\end{array}$ \\
\hline
\end{tabular}

Nota: $\mathrm{CT}$ = Categoria temática; $\mathrm{CEO}=$ Centro de Especialidades Odontológicas; $\mathrm{ACS}=$ Agente Comunitário de Saúde

Fonte: elaboração própria.

Nesta direção, coordenadores de CEOs da região revelaram a insuficiência financeira do repasse federal para custeio mensal do CEO, cabendo aos municípios arcarem com a maior parte do custeio. Nada obstante, o problema agudizava-se quando o gestor municipal restringia ou não tinha meios para assumir o gasto mensal, repercutindo em sucateamento do serviço (CT-5).

Além disso, existiam problemas na execução dos parcos recursos financeiros que, por sua vez, nem sempre era realizada por pessoal com conhecimento técnico acerca 
do funcionamento do CEO. O recurso federal, muitas vezes, não era executado pelas secretarias de Saúde dos municípios da região, ficando sob responsabilidade de outras secretarias e dependente das decisóes do executivo. Por conseguinte, mesmo quando as secretarias de Saúde conseguiam gerir o recurso, os coordenadores do $\mathrm{CEO}$ da regiáo revelaram não participar desse planejamento, restringindo sua função às questôes técnico-operacionais do serviço (CT-5).

Tais questôes refletem a existência de grande desigualdade entre os municípios do país em relação à capacidade de captação de recursos, execução de políticas de saúde e manutenção dos serviços, especialmente aqueles localizados no interior dos estados e com piores indicadores de saúde (MATTOS et al., 2014). Assim, a articulação dos sistemas municipais de saúde em redes regionalizadas seria uma estratégia organizativa, a fim de viabilizar a implantação dos CEOs regionais e, consequentemente, ampliar o acesso aos serviços de atenção especializada em saúde bucal (GODOI et al., 2017; SILVA JÚNIOR, 2019).

A análise da participação nas despesas com ações e serviços públicos de saúde no Brasil revela redução da participação relativa da União no total dos gastos públicos, pari passu estados e municípios ficam responsáveis pelo financiamento majoritário do setor (SOARES; SANTOS, 2014). Neste sentido, ainda que a atenção à saúde bucal seja a única área técnica que conta com incentivos federais para implantação e custeio de serviços especializados (KORNIS et al., 2011), a trajetória de subfinanciamento do SUS, bem como o percentual de gasto público per capita, em relação ao total dos gastos, sinalizam a insuficiência para sustentar uma política universal, equitativa e integral. Ainda que a PNSB tenha sido uma prioridade na agenda de governo (MACHADO et al., 2011), o aporte de financiamento contradiz a expectativa de abrangência desta política (FRANCO, 2017). Sendo assim, a implantação de CEO, na perspectiva regional, por meio de consórcios de saúde, seria uma alternativa para que municípios menores e com baixa capacidade financeira pudessem garantir açôes odontológicas especializadas à população (SILVA JÚNIOR, 2019).

$\mathrm{O}$ estado da Bahia, segundo gestores entrevistados, não conseguiu avançar nesse quesito, seja por meio de mecanismos de compartilhamento via Pactuação Programada Integrada (PPI), muito menos por meio de dispositivos de cogestão como o Contrato Organizativo de Ação Pública (COAP) que, em certa medida, poderia promover a integração regional dos serviços de saúde bucal e, consequentemente, ampliaria a oferta de atenção especializada à população (CT-6). 
Com o processo de descentralização das açóes e serviços do SUS a provisão da assistência seria de responsabilidade dos municípios e o gestor estadual deveria desempenhar estratégias para indução da regionalização (PEREIRA, 2009). Assim, a área técnica de saúde bucal, da Sesab, teria um trabalho central no exercício dessa função, uma vez que poderia conduzir e mediar as pactuaçóes entre os municípios em espaços como os Colegiados Intergestores Regionais (CIR) e fomentar a gestão compartilhada. Contudo, os técnicos da Sesab nem sempre conseguem estar presentes para exercer essa função mediadora (CT-7).

Neste ínterim, há um estímulo estadual para a formação de consórcios entre os municípios baianos para provisão compartilhada de serviços médicos, com o intuito de ampliar a oferta de atenção especializada à saúde, por meio da implantação de policlínicas públicas regionais (BAHIA, 2017a). Porém, tal estratégia não incluiu assistência odontológica, sinalizando que esse tipo de atenção não era prioridade para a política de regionalizaçáo do estado (CT-7). Na Bahia, não houve avanço devido ao descrédito dos gestores municipais nas pactuaçôes, por considerarem que o dispositivo não oferecia garantias de cumprimento dos acordos estabelecidos. Além disso, a rotatividade de secretários municipais de Saúde foi outro entrave para o estabelecimento de consórcios de saúde, pois como não houve a construção de fluxos e protocolos bem definidos e institucionalizados, porquanto a garantia do que foi pactuado ficava atrelada à figura do gestor que acordou, e não ao município.

Ainda assim, ao analisar a PPI de 2010 (BAHIA, 2010), em vigência no período da pesquisa, foi observada a existência de pactuaçôes entre os municípios da região de saúde, para alguns procedimentos de atenção especializada de saúde bucal. Tal fato, entretanto, ficava restrito ao plano formal (CT-8).

Náo por acaso, a insuficiência no financiamento do SUS também pode ser considerada como um entrave para a efetivação dos pactos, a partir do momento em que os valores pagos pela tabela do SUS estão aquém do custo real dos serviços de saúde (GOYA et al., 2017). Sendo assim, muito do que foi acordado ficou apenas no plano das intençóes, fragilizando a PPI como ferramenta de planejamento e a conformação de uma governança regional. Destaca-se que tal discussão não impacta na oferta dos CEO, uma vez que nesses serviços o financiamento das açóes não se dá por pagamento de produção. Todavia, as especialidades em saúde bucal poderiam ser ofertadas (e algumas foram pactuadas) mediante PPI (em modalidade distinta aos CEO). Desse modo, a discrepância dos valores da tabela SUS em relação ao 
mercado também contribuiu para que os gestores municipais não explorassem ou se encorajassem a ofertar especialidades odontológicas por outras vias.

Todas essas questões e, ainda, o atraso na regionalização tem gerado o isolamento e o arrefecimento da capacidade resolutiva dos sistemas locais de saúde (SANTOS, 2018). Todos os CEOs implantados na Bahia são municipais (BRASIL, 2019) o que demonstra uma dificuldade em conformar uma cooperação intergovernamental e uma integração regional desse tipo de serviço.

Por sua vez, além da reduzida oferta de atenção especializada na regiáo de saúde, um dos entrevistados destacou o baixo desempenho dos dois únicos CEOs implantados. Na mesma lógica, além de problemas relacionados ao cumprimento de metas, a implantação dos CEOs em alguns municípios baianos foi considerada um processo instável e muito dependente do propósito de determinados gestores locais em relação à saúde bucal (CT-9).

Tabela 3. Categorias temáticas (CT-5 a CT-9) segundo dados empíricos de gestores/ gerentes estaduais, regional e municipais

\begin{tabular}{|c|c|}
\hline $\begin{array}{c}\text { Categorias } \\
\text { temáticas }\end{array}$ & Estratos de entrevistas com gestores \\
\hline 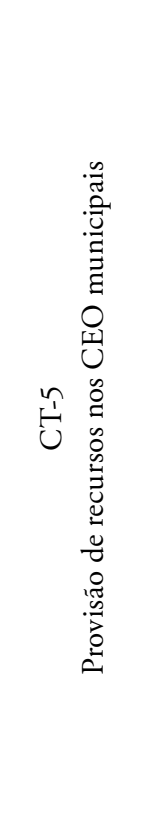 & $\begin{array}{l}\text { Porque, mais de } 80 \% \text { do CEO daqui é financiado pelo município. a contrapartida, hoje, é } \\
\text { federal, pois é o município que banca o serviço. Algo que a gente recebe aqui é R } \$ 23.100 \\
\text { por mês, que não paga nem a folha do [pessoal] nível médio. [...] o material, o insumo } \\
\text { odontológico é muito caro, os equipamentos são muito caros, a manutenção é cara, tudo é } \\
\text { muito caro. [...] aqui [no CEO], a gente nem sabe quanto chega por mês. Não passa nada } \\
\text { por aqui. É tudo lá na parte financeira que faz. [...] Não é a gente que gerencia não. O } \\
\text { gerenciamento, a previsão não é feita aqui (GM2). } \\
\text { [...] O dinheiro que entra no fundo municipal é R } \$ 9.700 \text { - que vem pro CEO. É muito } \\
\text { pouco! [...] não é nem o material. Mas o problema é que o município não quer dar a } \\
\text { contrapartida, quer tentar utilizar isso. Nunca vão conseguir! Igual no PSF [...] Eles querem } \\
\text { pagar o dentista com o dinheiro que vem, que o governo manda pra o dentista; não querem } \\
\text { completar, por isso que o valor [salário] é tâo baixo pro dentista na unidade [...] e é tudo } \\
\text { executado [...] pela prefeita, secretária e o pessoal do fundo municipal (GM3). } \\
\text { [...] tem município que deixa a secretaria de saúde administrar. Tem outros que é a secretaria } \\
\text { de administração responsável por todos os recursos da saúde. A maioria desses [municípios] } \\
\text { pequenininhos deixam bem centralizados mesmo; que é o secretário de administração } \\
\text { junto com o prefeito. Então, se precisa de qualquer coisa pra saúde tem que tá lá pedindo } \\
\text { e, às vezes, segura [...] na grande maioria dos menores [municípios] fica na secretaria de } \\
\text { administraçáo (GE4). }\end{array}$ \\
\hline
\end{tabular}

continua... 


\begin{tabular}{|c|c|}
\hline $\begin{array}{l}\text { Categorias } \\
\text { temáticas }\end{array}$ & Estratos de entrevistas com gestores \\
\hline 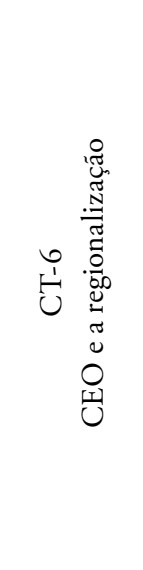 & $\begin{array}{l}\text { [...] municípios com população abaixo de trinta mil só podem ter CEO do tipo I. [...] se } \\
\text { você quiser o CEO maior, pode juntar com outros pra que chegue a população de trinta mil } \\
\text { e consiga implantar um. Mas a gente não conseguiu avançar nessas questóes de consórcio, } \\
\text { por conta das questôes de gestores. [...] esses [municípios] pequenininhos, a gente não } \\
\text { conseguiu avançar, mas ele pode ter [CEO]. Porque tem muitos municípios na Bahia, } \\
\text { acho que mais de cinquenta por cento, que têm populaçáo abaixo de trinta mil [...]. Que } \\
\text { pode muito bem comprar o serviço do município maior que já tem CEO. Através de PPI, } \\
\text { tem outros dispositivos, que a gente sabe que não funciona muito bem, mas que tem como } \\
\text { regionalmente discutir em CIR e solicitar (GE1). } \\
\text { [...] quando chega um município aqui [Sesab], com a população [menor] de trinta mil. [...] } \\
\text { a gente orienta que faça um consórcio. [...] pra garantir que funcione aquele CEO, mas } \\
\text { morre aí; a gente diz como é que faz, dá a sugestão de que no Ceará fazem desde [...], mas } \\
\text { não vai à frente (GE2). }\end{array}$ \\
\hline 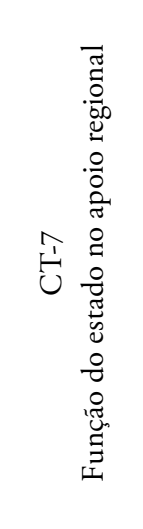 & $\begin{array}{l}\text { [...] a gente não consegue tá na CIR todo mês, pra chegar e dizer isso: "Oh, quem é canal, } \\
\text { quem não é". A gente já fez reuniōes assim, botou o mapinha da região, pegamos umas } \\
\text { tarjetinhas, "Aqui é CEO, cole lá quem tem CEO.”. Colava no mapa pra enxergar. "Quem } \\
\text { tem, quantas EqSF?" tinha umas casinhas, botava a EqSF". Cê via lá, aquele mapão, } \\
\text { naquele papel. "Quem tem UPA? Quem tem odontologia? Quem tem hospital que atende } \\
\text { paciente especial?" E tinha as carinhas do serviço, mesmo, e botava. "Bora ver aqui, esse é } \\
\text { o mapa da região". Aí, tinha os estudos de caso (GE1). } \\
{[\ldots] \text { como área técnica visitei no Ceará, que lá tem muitos CEO estaduais que foram através }} \\
\text { de consórcios, e a gente apresentou, mas o estado náo avançou em relaçâo à saúde bucal. } \\
\text { Atualmente, o estado dá o consórcio, mas nas policlínicas. [...] acho que [não há] vontade } \\
\text { política, porque [...] se realmente a política quer, vão e buscam, como aconteceu com as } \\
\text { policlínica (GE2). }\end{array}$ \\
\hline 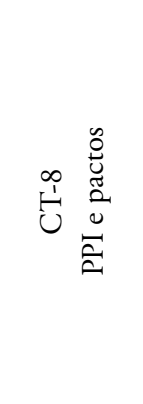 & $\begin{array}{l}\text { Infelizmente, é muito frágil, tanto a questão de pacto de indicadores, que tá ali como } \\
\text { meta, não existe punição se não cumprir, é a mesma coisa da PPI, não existe ninguém, } \\
\text { a gente até monitora, até lhe apoia, mas não existe nada, e não lhe obriga [a cumprir]. } \\
\text { É a mesma questão do consórcio [...] acordou, tudo certo. Dalí há um ano, quando ia } \\
\text { começar, saiu todo mundo [secretários de saúde], aí, senta os quatro de novo: "Não tenho } \\
\text { interesse, não" (GE1). } \\
\text { [...] não é só em relação a saúde bucal! É que a pactuação [geral] tá defasada [...] me lembro } \\
\text { que Conquista falava assim: "a gente vai pactuar por que é o jeito, mas não tenho como } \\
\text { garantir". Pactuava porque era obrigado (GE4). }\end{array}$ \\
\hline
\end{tabular}

continua... 


\begin{tabular}{|c|c|}
\hline $\begin{array}{c}\text { Categorias } \\
\text { temáticas }\end{array}$ & Estratos de entrevistas com gestores \\
\hline 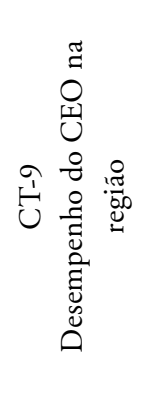 & $\begin{array}{l}\text { [...] existem dois CEO ali, que é o de Vitória da Conquista e o de Cândido Sales, todos dois, } \\
\text { como não é só lá, é [uma situação comum] nos CEO da Bahia. Eles não contemplam o que } \\
\text { deveria [...] a gente vê pela produção que são deficitários (GE2). } \\
\text { [...] varia muito com a gestão, né? Alguns, às vezes, a gente vai no município, aí, tá tudo } \\
\text { beleza, daqui a pouco volta, dois anos depois, já está acabado, destruído, né? [...] a gente } \\
\text { percebeu isso, que os CEO variam muito, às vezes, tá num processo bem legal, construiu o } \\
\text { fluxo. Daqui a pouco, chega uma nova gestão e muda tudo, demite todo mundo, volta tudo } \\
\text { do zero, quando a própria estrutura física não tá destruída, assim, sem manutenção, com } \\
\text { falta de equipamentos, com falta de instrumental, falta de insumo (GE3). }\end{array}$ \\
\hline
\end{tabular}

Nota: $\mathrm{CT}$ = Categoria temática; $\mathrm{CEO}=$ Centro de Especialidades Odontológicas; $\mathrm{ACS}=$ Agente Comunitário de Saúde

Fonte: elaboração própria.

Na mesma direção, a maioria dos CEOs do país não vem atingindo as metas ministeriais (GOES et al., 2012; CORTELLAZZI et al., 2014; LAROQUE; FASSA; CASTILHOS, 2015) e que os CEOs localizados em municípios de menor porte e baixo desenvolvimento humano têm piores desempenhos (GOES et al., 2012). Nesse percurso, chama atenção o fato de que a PNSB não tem nenhum dispositivo legal que assegure o cumprimento de suas diretrizes pelos governantes do país. Assim, todo o ciclo da política e, consequentemente, a efetivação da implantação dos CEOs, ficam muito atrelados a determinaçôes de cunho político-ideológico dos gestores da vez. Do mesmo modo, a implementação de políticas públicas de formulação e indução federal, como é o caso da PNSB, tem o protagonismo do governo local para o seu êxito (ROSSI; CHAVES, 2015), corroborando que o maior desafio para o SUS é político (PAIM et al., 2011).

Um estudo que avaliou o cumprimento de metas pelos CEOs implantados na regiáo de saúde de Jequié, na Bahia, considerou ruim o desempenho de todos os estabelecimentos analisados. Considerou como possível causa, problemas no gerenciamento do serviço, mas não associou com dados sociodemográficos e a cobertura de equipes de saúde bucal (SANTANA et al., 2015). Na mesma direção, Freitas et al. (2016) também não associaram o desempenho insatisfatório dos CEOs à cobertura de EqSF e EqSB ou ao IDH dos municípios, mas a falhas na gestão e organização desses serviços. 
Como possíveis fatores associados ao baixo desempenho dos CEOs no país, elencam-se: as formas de organização e gerenciamento dos processos de trabalho congruentes à construção das Redes de Atenção à Saúde (implantação de centros de regulação e formação de consórcios de saúde), bem como as características contextuais dos locais onde os CEOs estão situados (porte populacional, cobertura de ESF, IDHM, governabilidade, capacidade de governo) (MACHADO; SILVA; FERREIRA, 2015). Outro estudo que avaliou os CEOs do país encontrou desempenho ruim/regular nas regióes Nordeste, Sul e Sudeste, em municípios com menor IDHM, menor densidade demográfica e nos CEOs com menor tempo de implantação (CORTELLAZZI et al., 2014).

Segundo o boletim de saúde bucal divulgado pelo Observatório de Saúde Bucal da Universidade Federal de Pernambuco (UFPE, 2019), o desempenho dos CEOs baianos pode ser considerado como deficitários. $\mathrm{Na}$ Bahia, para a especialidade cirurgia oral menor e para o total de procedimentos básicos (para o atendimento de pacientes especiais), nenhum CEO atingiu a meta. Para o total de procedimentos gerais da especialidade endodontia, nenhum CEO tipo 3 cumpriu a meta e, ainda, com relação à meta de obrigatoriedade em realizar $20 \%$ de procedimentos específicos (obturação e/ou retratamento de dentes permanentes com 3 ou mais raízes), somente um CEO tipo 3 conseguiu cumprir.

O fraco desempenho dos CEOs baianos aponta falhas nas açôes relativas à coordenação de monitoramento de prestação dos serviços de saúde bucal e o apoio técnico que deveria desempenhar junto aos municípios, com a finalidade de superar possíveis fragilidades técnico-administrativas, políticas e financeiras. No entanto, foram referidos problemas para efetivação desse apoio, uma vez que havia insuficiência de pessoal para a área técnica de saúde bucal da Sesab (CT-10).

Nesta perspectiva, é compreensível que uma área técnica diminuta, alocada na secretaria estadual, sediada na capital, não seja capaz de acompanhar com proximidade todos os municípios do estado. Porém, entende-se que esse apoio poderia ser desempenhado via Núcleos Regionais de Saúde (NRS) que, a partir da publicação da Lei Estadual n ${ }^{\circ} 13.204$, substituíram as Diretorias Regionais de Saúde (DIRES) (BAHIA, 2014), as quais tinham como finalidade atender à descentralização de responsabilidades administrativas e delegação de atividades de gestão junto às instâncias municipais (BAHIA, 2008). Sendo assim, as DIRES teriam um protagonismo no apoio institucional aos municípios das regiôes de 
saúde (ALMEIDA; SANTOS, 2015), desenvolvendo açôes de cooperação técnica, avaliação e monitoramento (PINHEIRO; JESUS, 2014); por conseguinte, os NRS precisariam responder a essa demanda. No entanto, houve fragilidade nesse apoio a partir do momento que não existe dentro do NRS uma área técnica específica à saúde bucal.

De acordo com técnicos do NRS da região, o apoio do NRS seria apenas às açóes e serviços da APS. Assim, o monitoramento dos CEOs seria de competência da Área Técnica de Saúde Bucal (ATSB), alocada na Diretoria de Gestão do Cuidado (DGC) da Sesab (CT-10). Por esse prisma, pareceu existir uma compartimentalização das responsabilidades pelas açóes de saúde bucal por parte dos gestores estaduais e um vazio do estado no exercício das funçóes de acompanhamento e monitoramento dos serviços prestados nos CEOs municipais.

Ademais, a interação entre ATSB da Sesab e os técnicos do NRS figurou-se de forma pontual, não existindo uma agenda para açóes de acompanhamento dos CEO. Tais açóes poderiam amenizar as profundas assimetrias na capacidade de provisão de serviços de saúde no território, o que refletiria de forma positiva nos indicadores de desempenho desses serviços. Muitos contatos, por exemplo, foram feitos de forma emergencial, com o intuito de evitar o descredenciamento do CEO.

Sendo assim, o monitoramento da DGC nos CEOs municipais era realizado principalmente por meio dos sistemas de informação do SUS. Todavia, muitas vezes, os dados presentes no SIA/SUS não refletem a realidade dos serviços. Logo, seria necessário estar presente nos territórios, apoiando secretários de Saúde, sobretudo os coordenadores de saúde bucal/CEO (CT-10).

Não por acaso, os entrevistados destacam a importância de um auxílio técnico estadual para a organização do serviço e as consequências da sua ausência no desempenho desses serviços. De acordo com os gestores, o registro da produção do CEO ficou comprometido a partir do momento que atualizaçôes em normas e fluxos não eram repassados para os gestores do $\mathrm{CEO}$, gerando sub-registro da produtividade. Tal realidade evidencia que nem sempre os dados secundários do SIA/SUS refletem a realidade dos CEOs e, por conseguinte, fragilizam esse método de avaliação e monitoramento pelos supervisores à distância (CT-10).

Outrossim, ressalta-se que, embora as secretarias estaduais de Saúde monitorem a produção assistencial dos CEOs a competência da informação é do gestor local. 
Além disso, os procedimentos e metas estão dispostos em portaria ministeriais de acesso livre. Neste sentido, segundo o MS,

[...] os procedimentos da produção mínima mensal em cada especialidade são os identificados no Sistema de Gerenciamento da Tabela de Procedimentos, Medicamentos, Órteses, Próteses e Materiais Especiais do Sistema Único de Saúde (SIGTAP), com o atributo complementar "Monitoramento CEO" (BRASIL, 2010).

Os problemas elencados pelos gestores locais e estaduais atestam a fragilidade dos primeiros na condução gerencial, bem como apontam a desarticulação comunicacional entre eles na condução da política de saúde bucal. Ademais, esse tipo de monitoramento, via sistema de informação, é reforçado a partir do momento que o desempenho dos CEOs é avaliado de acordo a quantidade de procedimentos de certas especialidades como consta nas portarias ministeriais, as quais atrelam o custeio mensal federal ao cumprimento de tais metas. Sendo assim, problemas na gestão, nos processos de trabalhos e outros aspectos que fogem à capacidade da explicação numérica continuam não abordados e acabam refletindo no desempenho dos serviços. Por sua vez, quando ocorria o monitoramento do estado in loco, limitava-se a adequação da estrutura física dos estabelecimentos, o que não deixa de ser importante, mas não é condição exclusiva para a validação do bom desempenho de um serviço. Outrossim, percebeu-se um contingenciamento de recursos e precarização do trabalho na secretaria estadual e suas regionais destinadas à área técnica de saúde bucal, fragilizando as açôes de monitoramento e inviabilizando o apoio do estado aos CEOs municipais (CT-11).

$\mathrm{Na}$ mesma perspectiva, estudos que avaliaram o desempenho dos CEOs no Brasil evidenciaram a necessidade de definição de novos padrōes e cumprimento de metas para a avaliação e monitoramento, uma vez que, na maioria das regiōes, houve dificuldade em alcançar a quantidade de procedimentos estipulada pelas portarias ministeriais e, ainda, sugere a necessidade de fortalecimento da capacidade gerencial com ênfase no acompanhamento das açóes para a melhoria da qualidade (FIGUEIREDO et al. 2012). 
Tabela 4. Categorias temáticas (CT-10 a CT-11) segundo dados empíricos de gestores/ gerentes estaduais, regional e municipais

\begin{tabular}{|c|c|}
\hline $\begin{array}{l}\text { Categorias } \\
\text { temáticas }\end{array}$ & Estratos de entrevistas com gestores \\
\hline 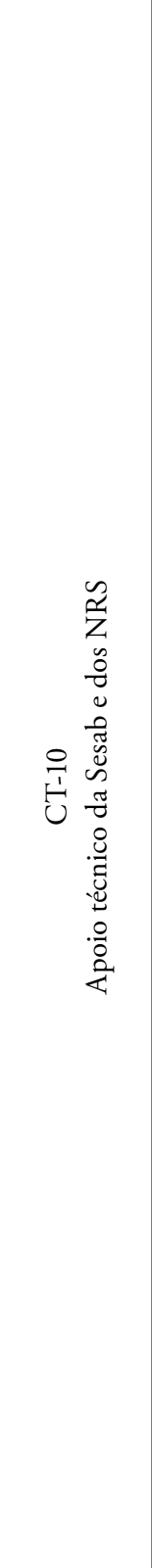 & 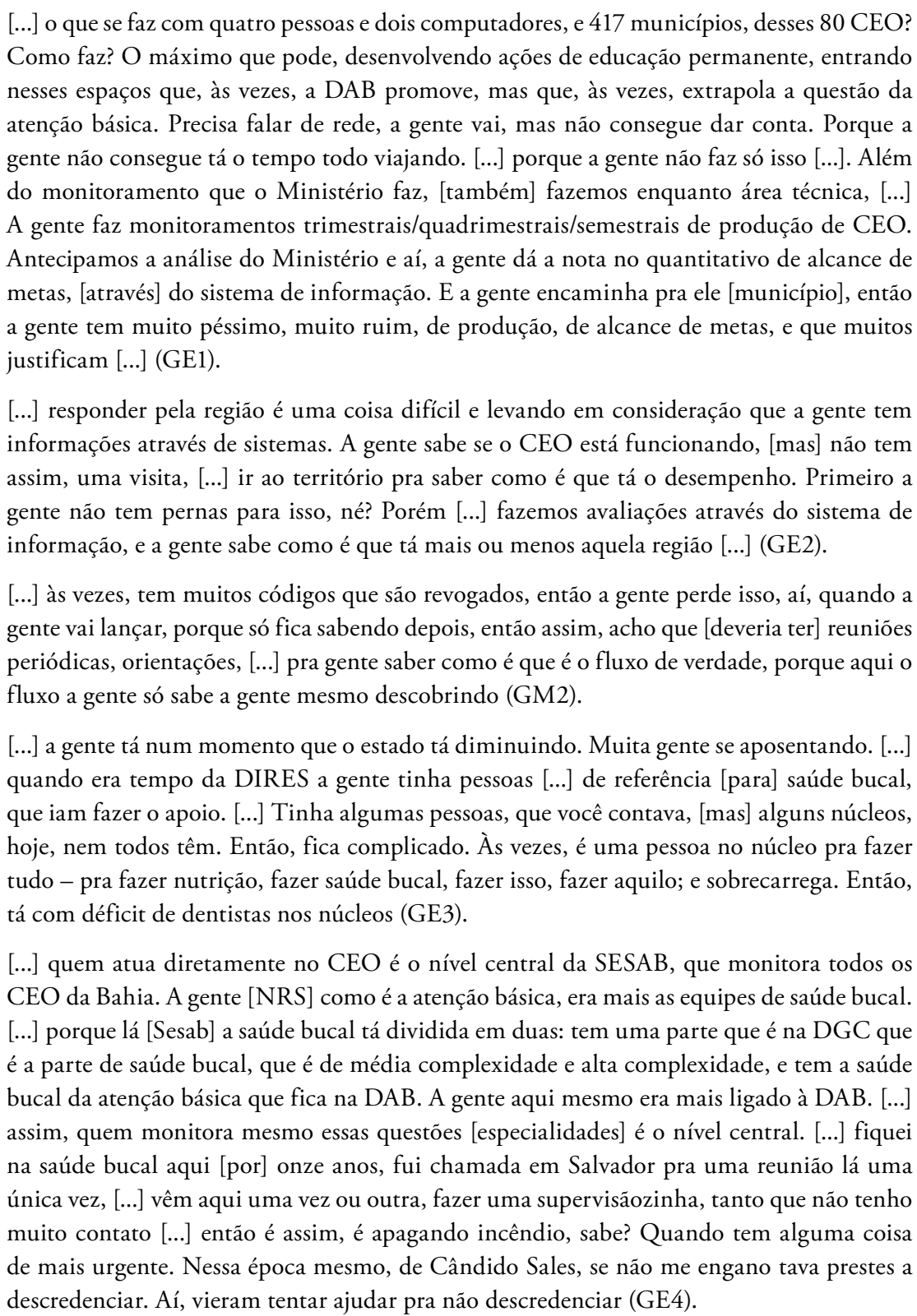 \\
\hline
\end{tabular}

continua... 


\begin{tabular}{|c|c|}
\hline $\begin{array}{l}\text { Categorias } \\
\text { temáticas }\end{array}$ & Estratos de entrevistas com gestores \\
\hline 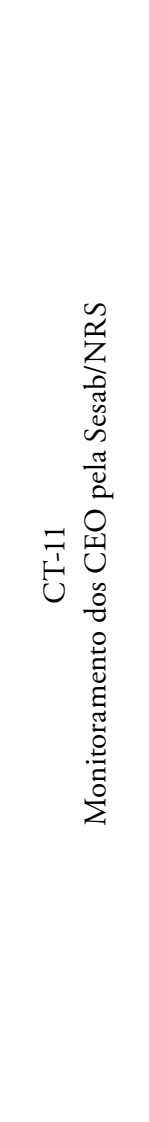 & 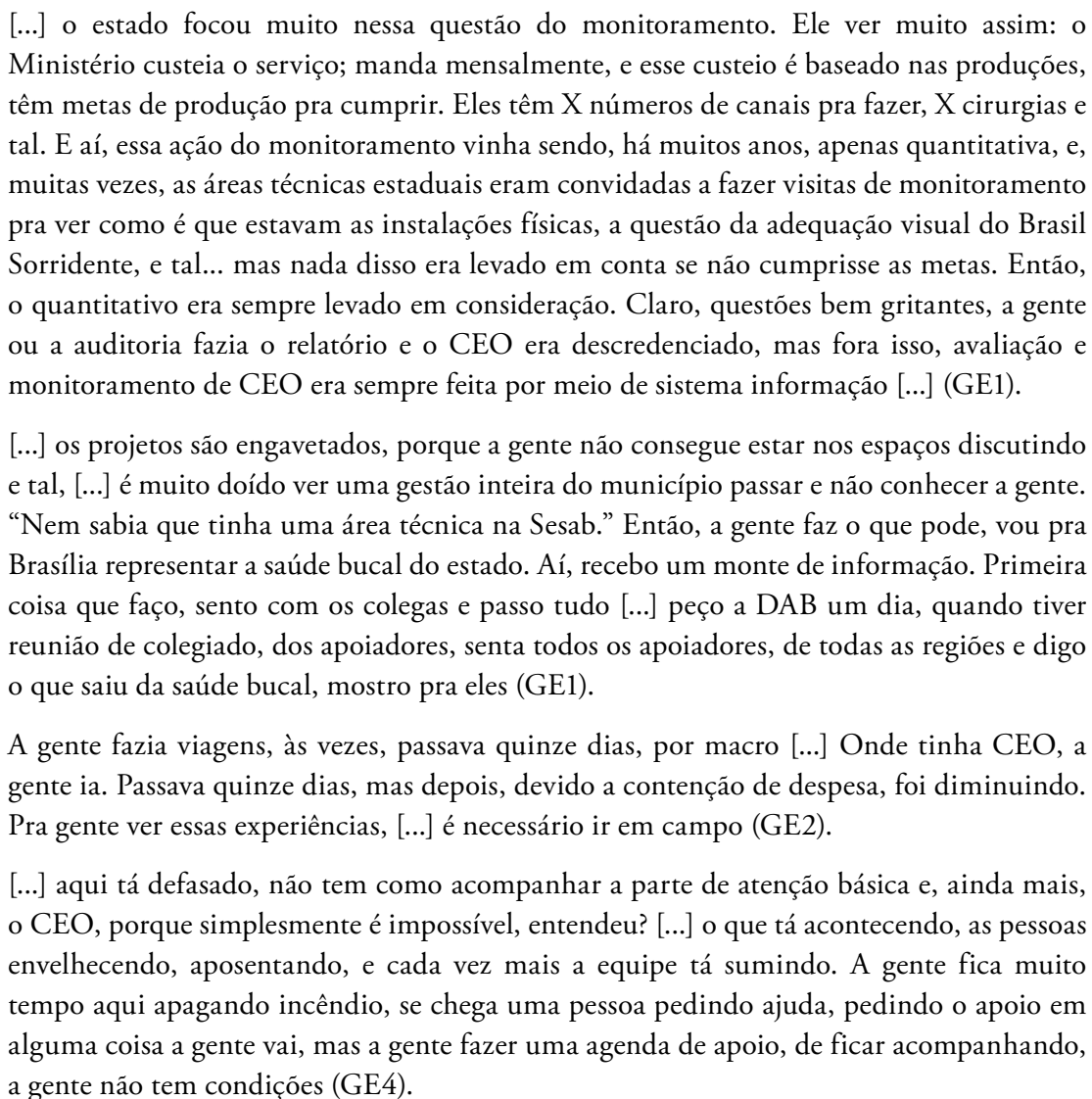 \\
\hline
\end{tabular}

Nota: $\mathrm{CT}=$ Categoria temática; $\mathrm{CEO}=$ Centro de Especialidades Odontológicas; $\mathrm{ACS}=$ Agente Comunitário de Saúde

Fonte: elaboração própria.

Não obstante, alguns serviços, sobretudo laboratórios de prótese dentária, foram implantados em alguns municípios sem conhecimento e prévio apoio da área técnica de saúde bucal do estado, sem planejamento e completamente alheio às possibilidades de oferta de serviços em determinados territórios (CT-12). Essa relação direta entre os municípios e o ministério também foi relatada por coordenadores municipais da regiáo. Tal prática pode ser entendida como consequência da deficiência do apoio técnico estadual. Entretanto, essa prática é uma norma ministerial e válida para todo o território nacional, sendo, portanto, opcional ao município buscar apoio estadual. 
A PNSB pareceu, igualmente, não ser prioridade para a agenda do governo baiano. Relatou-se, além do subfinanciamento para a área, a adoção de um modelo de atenção à saúde voltado aos procedimentos médicos de alta densidade tecnológica, em detrimento de outros modos de produção do cuidado (CT-13). Sendo assim, fica difícil criar expectativas de um apoio estadual para a implementação da política e, consequentemente, a ampliação da oferta de atenção especializada em saúde bucal por meio de CEO. Diante da fragilidade financeira e gerencial de muitos municípios, mesmo com pagamento por produçáo (diante da defasagem da tabela SUS), os gestores não se sentiam seguros/atraídos a ofertar por outras vias (não $\mathrm{CEO}$ ).

Nesta perspectiva, compreende-se que a implementação de uma política não depende apenas do dispositivo legal (ASSIS; JESUS, 2014). O dever do Estado em garantir o direito à saúde bucal já consta na Constituição de 1988, a partir do momento em que esta destaca que "a saúde é direito de todos e dever do Estado". Porém, ao considerar a existência de um orçamento limitado para o SUS, opta-se por destinar determinado recurso para certo programa, em detrimento de outro. Por esse prisma, assim como esteve presente na fala dos entrevistados, considera-se que o controle social teria papel fundamental na inserção da PNSB nas agendas de governo (CT-14).

Portanto, há a necessidade de "incorporação da sociedade civil no processo de institucionalização de políticas locais de saúde bucal” para que, dessa forma, haja garantia da perpetuidade dessas políticas, mesmo diante de interesses partidários ou de grupos sociais e econômicos incompatíveis com o bem público (BOTAZZO, 2013, p. 175). Ademais, há possibilidade de definição de prioridades e distribuição de recursos segundo o grau de necessidade dos grupos sociais específicos, em direção à equidade.

Entretanto, via de regra, a comunidade não incluía as demandas e os problemas da atenção em saúde bucal nas reuniôes dos conselhos municipais de saúde. Em contraposição, quando havia alguma reivindicação, o direito à saúde bucal não era, algumas vezes, legitimado pelo gestor e, neste sentido, era interpretado como assistencialismo e a população vista como ingrata (CT-14). Assim, dos 17 municípios que não implantaram $\mathrm{CEOs,} \mathrm{alguns} \mathrm{optaram} \mathrm{pela} \mathrm{oferta} \mathrm{de} \mathrm{certas} \mathrm{especialidades}$ odontológicas com a utilização de recursos próprios, mas com o acesso, ainda, bastante limitado, comprometendo a integralidade da atenção em saúde bucal da população na região (CT-15). 
Segundo um entrevistado, esse tipo de oferta foi observado também em outras regióes do estado. Inclusive em alguns municípios, os serviços de especialidades não são prestados necessariamente em estabelecimentos como o CEO (CT-15). Tal característica é igualmente encontrada em Minas Gerais, cuja produção de algum tipo de procedimento especializado foi realizada predominantemente $(70 \%)$ em unidades de APS (LINO et al., 2014).

\section{Tabela 5. Categorias temáticas (CT-12 a CT-15) segundo dados empíricos de gestores/ gerentes estaduais, regional e municipais}

\begin{tabular}{|c|c|}
\hline $\begin{array}{l}\text { Categorias } \\
\text { temáticas }\end{array}$ & Estratos de entrevistas dos gestores \\
\hline 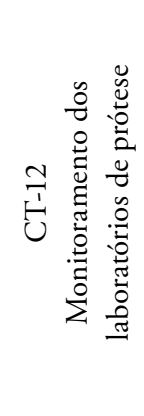 & $\begin{array}{l}\text { Pro laboratório, ele [município] entra no sistema da gestão, pede o laboratório, o Ministério } \\
\text { publica a portaria e fica por isso mesmo, inclusive, uma das grandes lutas dos estados, } \\
\text { quando tem reunióes de coordenadores, é que o estado não dá conta, não consegue prever } \\
\text { quantos laboratórios tem. Quando a gente vê, já é um pedido do Ministério pra ir visitar, } \\
\text { pra descredenciar. [...] Cê credencia no sistema e se não acompanhar a publicação de } \\
\text { portaria, às vezes, publica, dois meses depois, tá o município ligando, pedindo ajuda. "E } \\
\text { você tem laboratório?”. “Tenho, saiu publicado”. A gente não sabe, e não tem nem senha de } \\
\text { acesso ao sistema pra ver quem pediu. [...] Às vezes, o Ministério publica, passa recursos, e } \\
\text { o município passa um ano recebendo esse recurso e não consegue implantar o laboratório, } \\
\text { porque não teve essa conversinha anterior [...] (GE1). }\end{array}$ \\
\hline 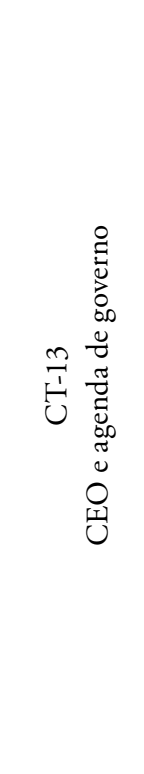 & $\begin{array}{l}\text { [...] pra o governo, independente do partido, saúde bucal não é a prioridade. [...] nessa atual } \\
\text { gestão foca muito nessas questóes de hospitais. [...] Uma outra coisa que fragiliza muito a } \\
\text { PNSB é, justamente, porque não é uma política instituída em portaria, como a PNAB [...]. } \\
\text { O Brasil Sorridente é apenas uma diretriz que lhe dá, mais ou menos um norte pra quem } \\
\text { for seguir, tanto pro gestor estadual quanto pro gestor municipal. Então, como não existe } \\
\text { uma portaria que institua, é muito frágil nesse sentido. [...] Então hoje, o estado não tem } \\
\text { uma política estadual [de saúde bucal] e, provavelmente, por isso, a gente não tem uma } \\
\text { política de cofinanciamento (GE1). } \\
\text { [...] um dos membros na época [na CIB] foi bem claro, dizendo: "Qualquer município que } \\
\text { quisesse implantar, náo tinha problema, o estado náo ia se opor, mas ficassem cientes de que } \\
\text { não haveria a contrapartida do estado". Isso foi dito há muitos anos, quando começavam, } \\
\text { os primeiros CEO, a serem implantados na Bahia (GE2). } \\
\text { [...] um dos problemas maiores é que as pessoas [gestores] não são sensibilizadas na questão } \\
\text { da importância da saúde bucal. Sempre deixam em segundo plano. [...] acham que saúde } \\
\text { bucal é se sobrar dinheiro. Porque todo o resto é mais importante, aí, se tiver dinheiro } \\
\text { bem, se não tiver, o que vai cortar primeiro é a saúde bucal, que acho que não entendem } \\
\text { a importância da saúde bucal na saúde geral [...] Falam de tudo [na CIR], mas de saúde } \\
\text { bucal, não é prioridade (GE4). }\end{array}$ \\
\hline
\end{tabular}

continua... 


\begin{tabular}{|c|c|}
\hline $\begin{array}{c}\text { Categorias } \\
\text { temáticas }\end{array}$ & Estratos de entrevistas dos gestores \\
\hline 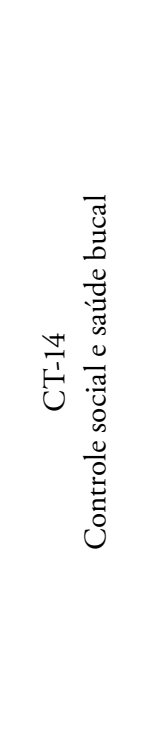 & $\begin{array}{l}\text { Pra odontologia, nesses } 4 \text { meses, a única coisa que foi colocada [na pauta do Conselho } \\
\text { Municipal de Saúde], a meu pedido, foi a abertura do pronto-atendimento odontológico, } \\
\text { pelo estado, na policlínica de Vitória da Conquista, ou na UPA de Vitória da Conquista. } \\
\text { Entendeu? Porque o estado não coloca esse atendimento (GM1). } \\
\text { Não! Não tem [...]. Esse tempo todo que tô no município - já tem quase sete anos -, } \\
\text { se escutei uma ou duas vezes foi muito, alguma demanda relacionada à saúde bucal, na } \\
\text { reunião do conselho [municipal de saúde] (GM2). } \\
\text { [...] o bairro que trabalho [além de acumular as funçóes de coordenadora do CEO e saúde } \\
\text { bucal, ainda atende em UBS] é [muito] carente. Entáo, praticamente é o bairro todo que } \\
\text { você tem que atender. Aí, tive reuniáo do conselho municipal, foi prestaçáo de contas pra } \\
\text { o conselho municipal, aí me questionaram, e, aí, brinquei: "Poxa! Vocês nunca tiveram } \\
\text { dentista, tinha que ir pra outro PSF, né? Ficar de madrugada pra conseguir uma vaga } \\
\text { [...] e estão reclamando que tá demorando muito de dar vaga! "Ah, já tem três meses que } \\
\text { liberou vaga" [reclamação de um usuário na reunião do CMS] [...] E aí, reclamam que } \\
\text { demora. Aí um menino falou assim "Nunca mais liberou". Eu falei "Não é assim". Então, } \\
\text { falei assim: "Poxa! [...] Vocês náo tinham nada. Eu coloquei isso aqui agora e vocês já estão } \\
\text { questionando". Tem hora que é melhor não ter do que dá o pouco, sabia? (GM3). }\end{array}$ \\
\hline 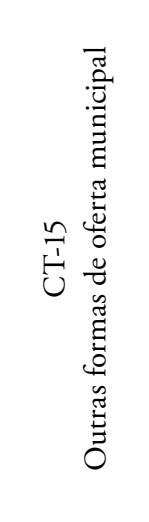 & $\begin{array}{l}\text { Alguns municípios fazem assim [...] colocam, não sei se ainda tá tendo também, mas acho } \\
\text { que até ano passado tinha um dentista pra endodontia, mas que, também, só fazia de dente } \\
\text { anterior, que não era dentro do CEO, mas ele [município] com recurso próprio pagava esse } \\
\text { dentista pra fazer endodontia. Aí, algum outro que queira colocar pra fazer cirurgia, aí } \\
\text { contrata um dentista pra fazer determinada cirurgia e tal com recurso próprio. Mas assim, } \\
\text { a maioria fica solto mesmo (GE4). } \\
\text { [...] municípios que não tem CEO implantado que informam obturação de canal. Às } \\
\text { vezes, tá fazendo ali, em uma policlínica, num outro centro especializado que não é CEO. } \\
\text { [município X de outra região] é um bom exemplo, pois tem um Centro Especializado } \\
\text { de Odontologia que não é CEO. Ele não é habilitado no ministério como CEO. Mas é } \\
\text { um Centro de Especialidade em Odontologia que oferta pediatria, oferta canal, mas por } \\
\text { iniciativa municipal (GE1). }\end{array}$ \\
\hline
\end{tabular}

Nota: CT = Categoria temática; $\mathrm{CEO}=$ Centro de Especialidades Odontológicas; ACS = Agente Comunitário de Saúde

Fonte: elaboração própria.

A atenção especializada odontológica pelo SUS pode ser realizada em instituiçóes habilitadas como CEO (regional ou municipal) ou, ainda, em estabelecimentos públicos do tipo "não CEO” (LINO et al., 2014). Outrossim, os CEOs surgiram como uma possibilidade para que os municípios organizassem uma rede de atenção 
capaz de atender a problemas de saúde bucal no âmbito das especialidades, de modo a permitir maior resolubilidade e interface com a APS (SILVA; GOTTEMS, 2017; MACHADO et al. 2015). Ainda assim, os municípios têm autoridade sanitária para decidir qual modalidade assistencial mais se adapta à realidade local. Para alguns municípios, o CEO regional pode não ser a melhor tipologia de serviço direcionado a ofertar atenção especializada ambulatorial por conta da demanda, distância para deslocamento da populaçáo a outro município, necessidade de transporte sanitário onerar açôes de "baixo custo", requerendo, assim, arranjos e inovações específicas para diferentes territórios. Em contraposição, o CEO regional, no Ceará, tem sido uma inovação e a estratégia preferencial para aumentar a oferta de especialidade odontológicas entre municípios que, de outra forma, não conseguiriam prover este nível de atenção (SILVA JÚNIOR, 2019).

Apesar dos problemas apontados no que se refere aos CEOs, esses serviços apresentam potencial de se estabelecerem como a principal estratégia para a garantia de assistência especializada e, por conseguinte, ampliar o escopo das açóes clínicas em saúde bucal. Nesta direção, sua implantação representou um aumento na produção de procedimentos especializados e ampliação da cobertura (CELESTE et al., 2014). Além disso, há experiências exitosas em outros locais do país (POSSAMAI, 2015; PIRES et al., 2015) demonstrando que os CEOs têm capacidade de atingir as metas estipuladas, cabendo, portanto, uma investigação e atuação nas principais causas daqueles que não têm apresentado desempenho satisfatório.

Por fim, constatou-se que a atenção especializada em saúde bucal não tem tido a mesma priorização na agenda federal, quando se comparam os dados da produção ambulatorial de serviços especializados (cirurgia oral, endodontia e periodontia), realizados em CEOs de todo país, nos períodos de 2003-2006, 2007-2010 e 20112014; houve redução no ritmo de crescimento, podendo representar repercussões futuras em sua manutenção (CHAVES; ROSSI; FREIRE, 2016). Por esse prisma, a PNSB enfrenta um panorama político desfavorável às políticas de proteção social, a partir da eleição de um governo cujas decisôes demonstram forte sintonia com os interesses do mercado, refletindo-se no contingenciamento de recursos destinados aos serviços públicos de saúde, que podem ter como repercussão o sucateamento dos CEOs e o comprometimento de sua continuidade. 


\section{Considerações finais}

Pôde-se perceber que a região de saúde de Vitória da Conquista apresenta uma carência de oferta de atenção especializada em saúde bucal, com poucas expectativas de mudança do cenário atual, sobretudo frente às atuais políticas de austeridade fiscal que reverberam na priorização da Política Nacional de Saúde Bucal nas agendas das três esferas de governo. Ainda assim, a saúde bucal é a única área técnica que conta com recursos financeiros federais por meio da política de incentivos ministerial (PAB variável) para implantaçáo e custeio mensal de serviços assistenciais especializados - CEOs. Tal questáo é emblemática, diante da dualidade de contingenciamento de recursos federais destinados ao SUS e a continuidade de repasses dos incentivos financeiros destinados aos $\mathrm{CEOs,} \mathrm{ou} \mathrm{seja,} \mathrm{pode} \mathrm{não} \mathrm{parecer} \mathrm{razoável} \mathrm{a} \mathrm{afirmativa} \mathrm{da}$ secundarização da PNSB, pelo menos na agenda federal.

Todavia, na $7^{\text {a }}$ Reunião de Pesquisa em Saúde Bucal Coletiva, pesquisadores, membros do grupo de temático em saúde bucal coletiva da Associação Brasileira de Saúde Coletiva (Abrasco), sintetizaram em carta aberta os perigos eminentes a PNSB diante da EC-95/2016 e de políticas ultraliberais. Para tanto, o grupo da Abrasco ressalta que o contingenciamento desconsidera aspectos cruciais: 1) aumento dos custos de manutençáo de um sistema de acesso universal; 2) envelhecimento populacional; 3) crescente incorporação tecnológica (insumos e medicamentos); e 4) desatualização de valores transferidos pela União para custear despesas com saúde bucal (ABRASCO, 2019).

No que diz respeito ao estado, o Plano Estadual de Saúde da Bahia 2016-2019 é omisso e genérico, sem previsão de orçamento específico, limitando-se ao apoio institucional e monitoramento de CEOs e LRPDs (BAHIA, 2016). Por sua vez, na região especificamente, a presença de apenas dois CEOs - ambos municipais compromete o alcance das açôes para os demais municípios e não consegue atender à demanda interna dos próprios municípios.

Os dados empíricos trouxeram alguns dos problemas e desafios para a implementação dos CEOs na região/estado, sinalizando que a superação dos problemas transcende às questôes locorregionais. Porquanto, envolve subfinanciamento para o custeio mensal dos serviços e questóes organizativas relacionadas aos entraves na efetivação da regionalização na Bahia, a qual poderia 
amenizar a escassez de recursos, estabelecendo uma cooperação intergovernamental capaz de construir uma rede de atenção em saúde bucal.

Quanto ao baixo desempenho dos CEOs implantados na regiáo, ressaltamse as potencialidades subaproveitadas dos Núcleos Regionais de Saúde e da Área Técnica de Saúde Bucal da Sesab. Neste sentido, o apoio técnico aos coordenadores municipais de saúde bucal/CEOs, a fim de superar possíveis fragilidades na gestão desses estabelecimentos de saúde, com o intuito de melhorar os resultados e alcançar o cumprimento de metas exigidos para esses serviços, permaneceu no âmbito do rito burocrático. ${ }^{1}$

\section{Referências}

ABRASCO. Associação Brasileira de Saúde Coletiva. $7^{a}$ Reunião de Pesquisa em Saúde Bucal Coletiva. Grupo de temático em Saúde Bucal Coletiva. Carta da Bahia: pelo Direito à Saúde Bucal. Salvador, 2019. Disponível em: < https://www.abrasco.org.br/site/gtsaudebucalcoletiva/ wp-content/uploads/sites/19/2019/07/Carta-da-Bahia_7RPSBC_2019.pdf>. Acessado em: 5 dez. 2019.

AGUILERA, S. L. V. U. et al. Articulação entre os níveis de atenção dos serviços de saúde na Região Metropolitana de Curitiba: desafios para os gestores. Revista Administração Pública, Rio de Janeiro, v. 47, n. 4, p. 1021-1039, jul-ago. 2013.

ALMEIDA, P. F.; SANTOS, A. M. Diálogos em busca de coordenação do cuidado: linha de chegada ou novo itinerário? In: SANTOS, A. M.; ALMEIDA, P. F.; SOUZA, M. K. B. (Orgs.). Atenção Primária à Saúde na coordenação do cuidado em regióes de saúde. Salvador: EDUFBA, 2015. p. 277-303.

ARAGÃO, M. N. Limites e desafios da implantaçâo de redes de atenção à saúde no contexto municipal. Dissertação (Mestrado em Saúde Coletiva) - Instituto de Saúde Coletiva, Universidade Federal da Bahia, Salvador, 2016.

ASSIS, M. M. A.; JESUS, W. L. A. de. Acesso aos serviços de saúde: abordagens, conceitos, políticas e modelo de análise. In: ASSIS, M. M. A.; ALMEIDA, M. V. G.(Orgs.). Acesso aos serviços e tecnologias no sistema único de saúde. Feira de Santana: UEFS, 2014. p. 43-75.

BAHIA (Estado). Lei no 11.055 de 26 de junho de 2008. Altera a estrutura organizacional e de cargos em comissão da Secretaria da Saúde do Estado da Bahia - SESAB e dá outras providências. Diário Oficial [da] Bahia, Salvador, 2008.

Lei Ordinária $n^{\circ}$ 13.204, de 11 de dezembro de 2014. Modifica a estrutura organizacional da administraçáo pública do poder executivo estadual e dá outras providências. Diário Oficial [da] Bahia, Salvador, 2014. 
- Resolução CIB no141/2010. Aprova a nova Programação Pactuada e Integrada do estado da Bahia - PPI-BA 2010 - e dá outras providências. Salvador, 2010.

. Secretaria da Saúde. Manual de acesso aos serviços de apoio, diagnóstico e tratamento das policlínicas regionais de saúde do estado da Bahia. Salvador, 2017a. 156p.

. Secretaria da Saúde. Manual orientador para os técnicos dos núcleos e bases regionais de saúde e coordenadores municipais. Bahia, 2017b. 55p.

. Secretaria de Saúde. Plano Estadual de Saúde 2016-2019. Revista Baiana de Saúde Pública. v. 40, supl. 3, out-dez. 2016, Salvador, 2016.

BOTAZZO, C. Diálogos sobre a boca. São Paulo: Hucitec; 2013. 380p.

BRASIL, P. R. C.; SANTOS, A. M. Desafios às açóes educativas das Equipes de Saúde Bucal na Atenção Primária à Saúde: táticas, saberes e técnicas. Physis: Revista de Saúde Coletiva, v. 28, n. 4, e280414, 2019.

BRASIL. Ministério da Saúde. Diretrizes da politica nacional de saúde bucal. Brasília, DF, 2004.

. Ministério da Saúde. Portal do Departamento da Atenção Básica. Disponível em: <http://aps.saude.gov.br/ape/brasilsorridente/cidadesatendidas>. Acesso em: 6 set. 2019.

. Ministério da Saúde. Portaria n ${ }^{\circ} 1.221$, de 18 de junho de 2013. Desabilita o Centro de Especialidades Odontológicas (CEO) do Município de Barra do Choça (BA). Brasília, DF, 18 jun. 2013.

. Ministério da Saúde. Portaria $n^{\circ} 1.464$, de 24 de junho de 2011. Altera o Anexo da Portaria no 600/GM/MS, de 23 de março de 2006, que institui o financiamento dos Centros de Especialidades Odontológicas (CEOs). Brasília, DF, 24 jun. 2011.

. Ministério da Saúde. Portaria $n^{\circ} 2.898$, de 21 de setembro de 2010. Atualiza o anexo da portaria no 600/GM, de 23/03/2006. Brasília, DF, 21 set. 2010.

CAMPOS, G. W. S. Efeitos paradoxais da descentralização no Sistema Único de Saúde. In: FLEURY, S. (Org.) Democracia, descentralização e desenvolvimento: Brasil e Espanha. Rio de Janeiro: FGV, 2006. p. 417-442.

CASOTTI, E. et al. Atenção em saúde bucal no Brasil: uma análise a partir da avaliação externa do PMAQ-AB. Saúde Debate, Rio de Janeiro, v. 38, n. especial, p. 140-157. 2014.

CELESTE, R. K. et al. Análise da produção ambulatorial em municípios com e sem centros de especialidades odontológicas no Brasil em 2010. Cadernos de Saúde Pública, Rio de Janeiro, v. 30, n. 3, p. 511-521, mar. 2014.

CHAVES, S. C. L. et al. Avaliação da oferta e utilização de especialidades odontológicas em serviços públicos de atenção secundária na Bahia, Brasil. Cadernos de Saúde Pública, Rio de Janeiro, v.27, n.1, p. 143-154, 2011. 
- Características do acesso e utilização de serviços odontológicos em municípios de médio porte. Ciência e Saúde Coletiva, Rio de Janeiro, v. 17, n. 11, p. 3115-3124, 2012.

. Política de Saúde Bucal no Brasil 2003-2014: cenário, propostas, ações e resultados. Ciência e Saúde Coletiva, v. 22, n. 6, p.1791-1803, 2017.

CHAVES, S.; ROSSI, T. A.; FREIRE, A. M. Implementação de serviços públicos odontológicos especializados no Brasil. In: CHAVES, S. C. L. (Org.) Politica de Saúde Bucal no Brasil: teoria e prática. Salvador: EDUFBA, 2016. p. 227-253.

CORTELLAZZI, K. L. et al. Variáveis associadas ao desempenho de Centros de Especialidades Odontológicas no Brasil. Revista Brasileira de Epidemiologia, São Paulo, v. 17, n. 4, p. 978-988, out-dez. 2014.

DEITOS, A. F. Avaliação da atenção especializada em saúde bucal. Dissertação (Mestrado Programa de Pós-Graduação em Ciências Odontológicas) - Faculdade de odontologia, Universidade de São Paulo. São Paulo, 2009.

DEMO, P. Avaliação qualitativa. Campinas, SP: Autores Associados, 2002. (Coleção polêmicas do nosso tempo).

FIGUEIREDO, N.; GOES, P. S. A. de. Construção da atenção secundária em saúde bucal: um estudo sobre os Centros de Especialidades Odontológicas em Pernambuco, Brasil. Caderno de Saúde Pública, Rio de Janeiro, v. 25, n. 2, p. 259-267, fev. 2009.

FIGUEIREDO, N.; GOES, P. S. A. de; MARTELLI, P. J. de L. (Orgs.). Os caminhos da saúde bucal no Brasil: um olhar quali e quanti sobre os Centro de Especialidade Odontológicas (CEO) no Brasil. 23. ed. Recife: EdUFPE, 2016.

FRANCO, D. H. Financiamento Público e Privado da Saúde Bucal no Brasil e no Mundo. 2017. 71f. Tese (Doutorado em Odontologia) - Universidade Estadual de Campinas, Piracicaba-SP, 2017.

FREITAS, C. H. S. de M. et al. Atenção em saúde bucal: avaliação dos centros de especialidades odontológicas da Paraíba. Saúde Debate, Rio de Janeiro, v. 40, n. 108, p. 131-143, 2016.

GODOI, H; ANDRADE, S. R.; MELLO, A. L. S. F. Rede regionalizada de atenção à saúde no Estado de Santa Catarina, Brasil, entre 2011 e 2015: sistema de governança e a atenção à saúde bucal. Cadernos de Saúde Pública, v. 33, n. 9, e00133516, 2017.

GOES, P. S. A. et al. Avaliação da atenção secundária em saúde bucal: uma investigação nos centros de especialidades do Brasil. Cadernos de Saúde Pública, Rio de Janeiro, v. 28, p. 81-89, 2012.

GOYA, N. et al. Percepçóes de gestores estaduais da saúde sobre o contrato organizativo da ação pública da saúde no Ceará. Ciência e Saúde Coletiva, Rio de Janeiro, v. 22, n. 4, p. 1235-1244. 2017. INSTITUTO BRASILEIRO DE GEOGRAFIA E ESTATÍSTICA. Pesquisa nacional de saúde 2013: acesso e utilizaçâo dos serviços de saúde, acidentes e violências. Brasil, grandes regiōes e unidades da federação / IBGE, Coordenação de Trabalho e Rendimento. Rio de Janeiro, 2015. 
KORNIS, G. E. M.; MAIA, L. S., FORTUNA, R. F. P. Evolução do financiamento da atenção à saúde bucal no SUS: uma análise do processo de reorganização assistencial frente aos incentivos federais. Physis Revista de Saúde Coletiva, Rio de Janeiro, v. 21, n. 1, p. 197-215, 2011.

LAROQUE, M. B. et al. Avaliação da atenção secundária em saúde bucal do centro de especialidades odontológicas de Pelotas, Rio Grande do Sul, 2012-2013. Epidemiologia Serv. Saúde, Brasília, v. 24, n. 3, p. 421-430, 2015.

LINO, P. A. et al. Análise da atenção secundária em saúde bucal no estado de Minas Gerais, Brasil. Ciência e Saúde Coletiva, Rio de Janeiro, v. 19, n. 9, p. 3879-88. 2014.

MACHADO, C. V.; BAPTISTA, T. W. F.; NOGUEIRA, C. O. Políticas de saúde no Brasil nos anos 2000: a agenda federal de prioridades. Cadernos de Saúde Pública, Rio de Janeiro, v. 27, n. 3, p.521-532, 2011.

MACHADO, F. C. de A.; SILVA, J. V.; FERREIRA, A. F. Fatores relacionados ao desempenho de Centros de Especialidades Odontológicas. Ciência e Saúde Coletiva, Rio de Janeiro, v. 20, n. 4, p. 1149-1163, 2015.

MANFredini, M. A. et al. Assistência Odontológica Pública e Suplementar no Município de São Paulo na Primeira Década do Século XXI. Saúde Soc. São Paulo, v. 21, n. 2, p. 323-335. 2012.

MATTOS, G. C. M. et al. A inclusão da equipe de saúde bucal na Estratégia Saúde da Família: entraves, avanços e desafios. Ciência e Saúde Coletiva, Rio de Janeiro, v. 19, n. 2, p. 373-382, 2014.

MENDES, Á.; MARQUES, R. M. O financiamento da Atenção Básica e da Estratégia Saúde da Família no Sistema Único de Saúde. Saúde debate, Rio de Janeiro, v. 38, n. 103, p. 900-916, 2014.

MINAYO, M. C. S. O desafio do conhecimento: pesquisa qualitativa em saúde. 14. ed. São Paulo: Hucitec, 2014, 407p.

MOREIRA, T. P. et al. Dentes da desigualdade: marcas bucais da experiência vivida na pobreza pela comunidade do Dendê, Fortaleza, Ceará, Brasil. Cadernos Saúde Pública, Rio de Janeiro, v. 23, n. 6, p. 1383-92, 2007.

NARVAI, P. C.; FRAZÃO, P. Saúde bucal no Brasil: muito além do céu da boca. Rio de Janeiro, RJ: Fiocruz, 2008.

NEUMANN, D. G. Modelo de Atenção em Saúde Bucal na Saúde Suplementar: uma análise a partir das operadoras de planos odontológicos no Brasil. 2014. 262f. Tese (Doutorado em Odontologia) - Programa de Pós-Graduação em Odontologia, Universidade Federal de Santa Catarina, Florianópolis, 2014.

ORGANIZAÇÃO PAN-AMERICANA DA SAÚDE. O desafio da implantação de redes de atenção à saúde no Brasil. In: ______. A atenção à saúde coordenada pela APS: construindo as redes de atenção no SUS: contribuiçôes para o debate. Brasília, 2011. 
PAIM, J. et al. The Brazilian health system: history, advances, and challenges. Lancet, London, v. 377, n. 9779, p. 1778-97, maio 2011.

PEREIRA, A. M. M. Dilemas federativos e regionalização na saúde: o papel do gestor estadual do SUS em Minas Gerais. 2009. 133f. Dissertação (Mestrado em Saúde Pública) - Escola Nacional de Saúde Pública, Fundação Oswaldo Cruz, Rio de Janeiro, 2009.

PERES, M. A. et al. Desigualdades no acesso e na utilização de serviços odontológicos no Brasil: análise do Sistema de Vigilância de Fatores de Risco e Proteção para Doenças Crônicas por Inquérito Telefônico (VIGITEL 2009). Caderno Saúde Pública, Rio de Janeiro, v. 28, p. 90-100, 2012.

PINHEIRO, M. E. C.; JESUS, L. M. M. Apoio institucional como diretriz de gestão da $7^{\circ}$ Diretoria Regional de Saúde, Bahia, Brasil. Interface, Botucatu, v.18, p. 1135-1143, 2014.

PINTO, V. G. Bases para uma saúde bucal de caráter coletivo. In: Saúde Bucal Coletiva. 6. ed. São Paulo: Santos, 2013. p. 1-22.

PIRES, A. L. C. et al. Atenção secundária em saúde bucal no Rio Grande do Sul: análise descritiva da produção especializada em municípios com Centros de Especialidades Odontológicas com base no Sistema de Informaçóes Ambulatoriais do Sistema Único de Saúde. RFO, Passo Fundo, v. 20, n. 3, p. 325-333, set./dez. 2015.

POSSAMAI, T. et al. Açóes secundárias em saúde bucal: análise do centro de especialidades odontológicas de um município do interior do paraná, Brasil. Revista APS, Juiz de Fora, v. 18, n. 3, p. 266-272, jul-set. 2015.

ROSSI, T. R. A.; CHAVES, S. C. L. Implementação da atenção especializada em saúde bucal em dois municípios na Bahia, Brasil. Saúde Debate, Rio de Janeiro, v. 39, n. esp, p. 196-206, dez. 2015.

SANTANA, D. A. et al. Desempenho dos centros de especialidades odontológicas de uma região de saúde da Bahia. Caderno de Saúde Coletiva, Rio de Janeiro, v. 23, n. 3, p. 261-267, 2015.

SANTOS, A. M. et al. Linhas de tensões no processo de acolhimento das equipes de saúde bucal do Programa Saúde da Família: o caso de Alagoinhas, Bahia, Brasil. Cadernos de Saúde Pública, v. 23, n. 1, p. 75-85, 2007.

SANTOS, A. M. Redes regionalizadas de atenção à saúde: desafios à integração assistencial e à coordenação do cuidado. Salvador: EDUFBA, 2018.

SANTOS, A. M.; ASSIS, M. M. A. Saúde bucal: da fragmentação à integralidade. Feira de Santana: UEFS, 2010.

SANTOS, A. M.; GIOVANELLA, L. Governança regional: estratégias e disputas para gestão em saúde. Revista de Saúde Pública, v. 48, n. 4, p. 622-631, 2014. 
SHERER, C. I.; SCHERER, M. D. A. Avanços e desafios da saúde bucal após uma década de Programa Brasil Sorridente. Revista de Saúde Pública, v. 49, n. 98, 2015.

SILVA JUNIOR, C. L. Análise da Implementação dos Centros de Especialidades Odontológicas Regionais no Estado do Ceará, Brasil. 2019. 145f. Dissertação (Mestrado em Saúde Coletiva) Programa de Pós-Graduação em Saúde Coletiva, Universidade Federal Fluminense, Niterói, 2019.

SILVA, A. N. et al. Modelos Assistenciais em saúde e saúde bucal. In: SILVA, A. N.; SENNA, M.A. A. de. (Orgs.). Fundamentos em saúde bucal coletiva. Rio de Janeiro: Medbook, 2013. p. $65-90$.

SILVA, H. E. C.; GOTTEMS, L. B. D. Interface entre a Atenção Primária e a Secundária em odontologia no Sistema Único de Saúde: uma revisão sistemática integrativa. Ciência e Saúde Coletiva. v. 22, n. 8, p. 2645-2657, 2017.

SOARES, A.; SANTOS, N. R. dos. Financiamento do Sistema Único de Saúde nos governos FHC, Lula e Dilma. Saúde Debate, Rio de Janeiro, v. 38, n.100, p. 18-25, mar. 2014.

TAVARES, R. P. et al. A Organização do acesso aos serviços de saúde bucal na estratégia de saúde da família de um município da Bahia. Saúde Debate, Rio de Janeiro, v. 17, n. 99, p. 628635. 2013.

UNIVERSIDADE FEDERAL DE PERNAMBUCO (UFPE). Observatório de Saúde Bucal. Monitoramento do cumprimento de meta dos Centros de Especialidades Odontológicas em 2017: Dados Nacionais. Disponível em: <https://www.ufpe.br/cecol/observatorio>. Acesso em: 20 jan. 2019.

YIN, R. K. Estudo de caso: planejamento e métodos. Porto Alegre: Bookman, 2005.

\section{Nota}

${ }^{1}$ T. P. R. Chequer realizou a pesquisa de campo, análise dos dados e redação do artigo. A. M. dos Santos orientou a pesquisa e realizou a revisão do artigo. 


\section{Abstract}

\section{Organization of Dental Specialty Centers in a Health Region in Bahia, Brazil}

This article analyzes the organization of the Dental Specialty Centers (CEO) in a health region and discusses the implementation of the CEO's in Bahia. This is a case study with a qualitative approach using semi-structured interviews and with managers dealing directly with oral health policies at the state, regional and municipal level. In addition, the documentary analysis was used to complement and establish interconnection with the data produced in the interviews. Thematic content analysis guided the interpretation of results. Much of the Bahia's population remains without receiving the specialized public services of oral health, without expectations of the implementation of new CEOs both in the municipal and in the regional levels. There was difficulty in implementing an intermunicipal cooperation in the region for shared actions in oral health. In addition, the state Government's agenda did not foster regional CEO arrangements. Thus, there is a fragmentation of care, without guarantees in the continuity of oral health care and, as a result, the decrease in the resolution capacity of local health systems.

> Keywords: oral health; dental specialties; regional health planning; health services administration. 